\title{
Pricking the Dinosaur
}

\section{Dear Reader,}

You could almost begin to feel sorry for the poor milkmaid Perrette in the fairy story with her pail of milk, because she has become synonymous with human stupidity. All she did was to work out in her head on the way to market what she could expect to earn from her milk. Unfortunately, she spilled it all before she got there and her daydreams came to nothing. Fortunately, she is simply a character in a fable.

By contrast, the fairy tale of the clean electric car seems to have turned into reality in the minds of green campaigners. It is powered, as we all know, by electricity and therefore it produces no exhaust gases that will harm the climate. This makes it environmentally friendly. When I heard ill-informed statements of this kind in the past, I would generally just roll my eyes and think to myself "... where I come from we get it out of the wall socket," but now I have started clenching my fist in my trouser pocket, because electricity has become much less clean in 2021. During the first six months of the year, the amount of electricity generated from conventional sources in Germany was 20.9 \% up on the same period in 2020. It made up $56 \%$ of the total electricity generation and the amount produced by coal-fired power stations increased by $35.5 \%$. Do we really think we can achieve our climate targets with electric cars? I haven't laughed so much in a long time.

But there is perhaps the possibility of charging BEVs with genuinely green energy. All we need to do is stick a pin in the plump, complacent dinosaur that is the German automotive industry. It may be that this pinprick has already happened, because an industry standard came into force in China last month that regulates exchangeable batteries. Instead of being forced to wait for hours at charg- ing stations, drivers could change their batteries in just a few minutes and the replacements would have been charged with $100-\%$ green energy during off peak periods. Admittedly, the idea is not exactly a new one and has been repeatedly dismissed by German carmakers. They claim that the system of exchangeable batteries in cars "is not technically feasible" and that a "centrally planned economy" would be needed to run a system of this kind. Both of these claims are, of course, ridiculous, particularly as the industry has used almost identical arguments about catalytic converters in the past.

It will be interesting to see whether Autosaurus germanicus leaps into action more quickly than we might expect if their domestic competitors start taking small steps in this direction in line with the laws of the market economy and then celebrate their first successes. As recently as November, a German manufacturer came out with just such an exchangeable battery system. Bring me the popcorn, it could be exciting...

With best regards,

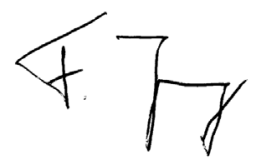

Frank Jung

Editor

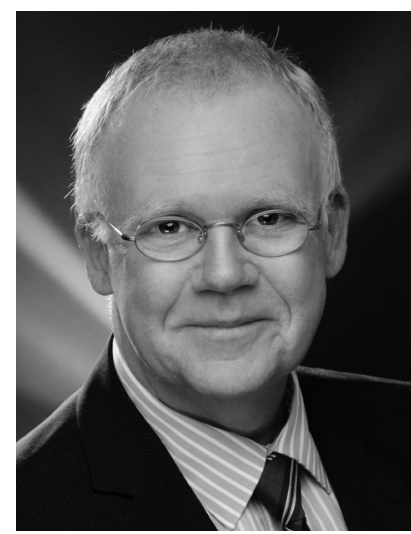

VIRTUALIZATION OF VALIDATION

\section{Mastering complexity.}

Rapidly increasing system complexity and the related demand for quality and sustainability require new, innovative validation methods. Intelligent Verification and Validation - this means holistic test strategies and intelligent test automation. With our methodological expertise, we support you as an engineering partner in your verification and validation strategy across all test levels and develop a customized test concept using the latest technologies such as $\mathrm{CI} / \mathrm{CD}$ on cloud infrastructures with virtual control units.

\section{ITK Engineering GmbH -}

Your partner for virtual validation and secure testing in the cloud.

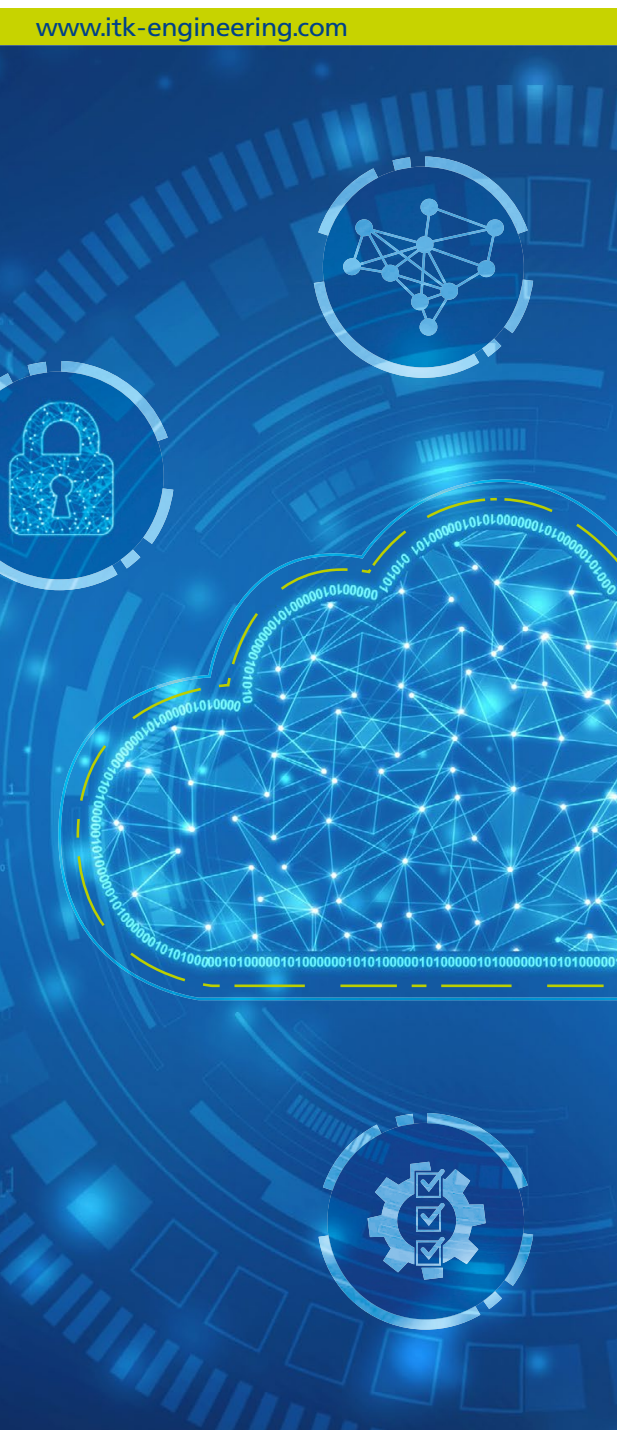

